\title{
A critique of traditional approaches to seaweed distribution in light of the development of vicariance biogeography
}

\author{
David Garbary \\ Department of Biology, St. Francis Xavier University; Antigonish, Nova Scotia, B2G 1CO, \\ Canada
}

\begin{abstract}
An overview of the primary approaches to seaweed biogeography is provided in light of the development of vicariance biogeography. Each approach is discussed with particular regard to the extent to which the methods and objectives are compatible with vicariance. Ecological biogeography is considered an offshoot of ecology and physiology and is more appropriate in determining current distributions of organisms and aspects of physiological ecology rather than the speciation history of monophyletic groups. The R/P quotient of Feldmann and distribution of algal life-forms do not fall within the aegis of vicariance and are considered useful only in a descriptive sense. The examination of seaweed spans propounded by Pielou is considered flawed because of the lack of dependence on monophyletic groups. The floristic school of analysis of many seaweed biogeographers is analagous to the panbiogeography of Croizat, and provides the basis for the more concrete phylogenetic hypotheses that are the basis for vicariance analysis. The latter is considered the best methodology for studying the relationship between patterns of cladogenesis and the distribution of constituent taxa.
\end{abstract}

\section{INTRODUCTION}

Seaweed biogeography has developed considerably since Lamouroux (1826) provided the first account of this topic. In that paper, Lamouroux outlined some of the primary problems in algal biogeography: species diversity, latitudinal changes in vegetation composition, and even the disjunct nature of generic distributions. These and related topics provided the basis for the summary of seaweed biogeography and physiological ecology by Lüning (1985). Since the early 19th century, considerable understanding of the seaweed floras in most parts of the world has been made and led to the observations that the floras of particular regions show differences and similarities with other parts of the world (e.g. Schneider, 1976; Parsons, 1985). Until recently, many biogeographic investigations, whether of whole floras or particular groups within floras, were limited to this kind of discussion, and very little in the way of historical and or evolutionary explanations have been attempted (cf. Hommersand, 1972, and Nicholson, 1979, for exceptions).

In recent years, seaweed biogeography has progressed from a primarily descriptive endeavour to a more experimental and analytical one. Experimental approaches have made possible the formulation and testing of hypothesis relating to the distribution of algae. Most of these hypotheses have dealt with the nature of environmental factors 
(primarily temperature) responsible for limiting the distribution of the algae, and the correlation between the actual distribution and the physiological tolerance of the organisms (e.g. Yarish et al., 1986).

Over the last twenty years a methodology for biogeographic analysis (i. e. vicariance biogeography) has been developed which evaluates the patterns of cladogenesis (i. e. phylogenetic trees) to the distributions of organisms (cf. Nelson \& Platnick, 1981, and Wiley, 1981, for introduction and basic theory). In this paper I will review some of the approaches to seaweed biogeography that have been utilized in recent years and discuss them in light of the development of vicariance biogeography. I discuss how various approaches to biogeography are limited by their failure to consider cladistic relationships and how they can generate stronger hypotheses by applying such methodology. This is a theoretical paper that discusses some of the questions that can be investigated using the methodology, rather than an actual application. Several examples and a further elaboration of the methodology are described by Lindstrom (1987).

\section{PHYSIOLOGICAL ECOLOGY AND DISTRIBUTION}

Under this heading I include studies of ecological biogeography that attempt to explain the current distribution of organisms primarily as a function of the environmental factors that produce barriers at the limits of the distributions; some recent examples are Yarish et al. (1984, 1986); Lüning (1984); McLachlan \& Bird (1984). The environmental factor considered most important is temperature, although one study by Bird \& McLachlan (1986) implicated salinity as a factor in species distributions. The primary objective of these investigations is to correlate the distribution limits of an organism with a temperature phenomenon occurring in that area. For the most part there is good agreement between the theoretical distribution limits determined from laboratory studies and the actual limits of the species. It is not surprising that species are generally adapted to the areas in which they grow, and the above work has certainly demonstrated this. One generalization thas has come out of this work is that species can be categorized into one of a number of 'biogeographic temperature groups'. Aspects of temperature that form the boundaries differ from one species to another and these provide the basis for the biogeographic temperature groups. Another interesting point is that species may (Yarish et al. 1986) or may not (Rietema \& van den Hoek, 1984) form ecotypes.

Although the above studies and generalizations have provided interesting ecological insights, they have not had a major impact on historical biogeography. This is partly because these were not among the objectives of the original studies and also because of the difficulty in gathering data from a sufficiently large sample of species for meaningful interpretations. What would be required in the analysis is the temperature responses of sister species in genera that are widely dispersed through the different biogeographic temperature regions. This presumes a clear knowledge of the present distributions and the phylogenetic relationships within each group. Given this information and the temperature responses, if sister species tended to occur on either side of a primary temperature barrier (i.e. in different biogeographic provinces) that had been previously identified, then the temperature responses have some evolutionary importance to the extent that they are reflected in the speciation events. However, if the sister species tend to occur within particular temperature regions, then this provides for wider generalizations in that 
it indicates a stronger genetic component for the temperature response that can be used as a synapomorphy in generating cladograms. It also would imply a common evolutionary and distributional history for the monophyletic groups concerned. To provide for a simplistic example, the cold-water flora shown by Lüning (1984) for Helgoland suggests that the history of these species should be examined from the context of an Arctic or North Pacific origin rather than a warm temperate Atlantic origin. I regard this as simplistic because the extensive taxonomic and distributional data for these species would suggest this alone, and it is merely supported by the temperature responses. Cladistic analyses should be useful in the examination of such hypotheses.

\section{FLORISTIC ANALYSIS}

\section{The $\mathrm{R} / \mathrm{P}$ ratio and life forms}

The R/P ratio (number species of Rhodophyta/number of species of Phaeophyta) was initially formulated by Feldmann (1937) to describe the floristic affinity of a flora in terms of its relative tropical or polar nature. Floras with a low value (ca 1) were polar and those with a high value (4 or more) were considered tropical; intermediate values were representative of temperate regions. Most floras in the north Atlantic seem to correspond to this model, confirming that red algae become more diverse relative to brown algae as one approaches the tropics. This ratio was modified by Cheney (1977) to include the green seaweeds $[(R+C) / P]$ and this was thought to provide greater resolution compared to Feldmann's original index. The Cheney index is an inverse of the proportion of brown algae in a flora, and is simply a function of the diversity of Phaeophyta in a flora.

Although the Feldmann \& Cheney ratios may have some predictive value for the north Atlantic, they are not particularly useful in other parts of the world. An example of this problem is in the eastern Pacific with its greater predominance of Rhodophyta. Thus a comparison of the two ratios for a series of floras of urban areas in western North America from Vancouver to Los Angeles (Table 1) shows no apparent correlation with latitude and indicates that Vancouver has virtually a 'tropical flora' according to both indices. In one index, Vancouver and Los Angeles have almost the same values (3.9 and 4.0 respectively), and in the second, the index for Vancouver is much higher ( 5.5 versus

Table 1. A comparison of the Feldmann (1937) and Cheney (1977) ratios of floristic composition for Vancouver, Seattle, San Francisco Bay and Los Angeles. Note: data for Vancouver from Garbary \& Golden (personal collections, 1980-1983), for Seattle from Thom et al. (1976), for San Francisco Bay from Silva (1979), and for Los Angeles from Widdowson (1971) and Setzer (1974)

\begin{tabular}{|lcccc|}
\hline \multicolumn{1}{c}{ Taxa } & Vancouver & Seattle & San Francisco & Los Angeles \\
\hline Chlorophyta & 53 & 40 & 34 & 15 \\
Phaeophyta & 33 & 27 & 27 & 26 \\
Rhodophyta & 128 & 78 & 94 & 103 \\
Total & 214 & 145 & 155 & 144 \\
R/P & 3.9 & 2.9 & 3.5 & 4.0 \\
R + C)/P & 5.5 & 4.4 & 4.7 & 4.5 \\
\hline
\end{tabular}


4.5). Bolton (1986) also pointed out the limitations of using such indices for southern African floras.

In summary, the Feldmann and Cheney indices are apparently informative for the North Atlantic Ocean where a trend is present; however, this is not based on any general principle that can be applied elsewhere. There do not seem to be any strong evolutionary or ecological hypotheses that can be generated through such calculations and use of the original figures, $i$. e. the absolute numbers of red, brown and green algal species in a given flora, is probably more informative. If either of the above indices do have any ecological meaning, it is strictly descriptive in nature, and has no significance in an evolutionary sense. Similarly, changes in life-form spectra along environmental and/or climatic gradients might provide a non-taxonomic description of the flora (Chapman \& Chapman, 1976; Garbary, 1976), but again the examination of life form spectra allows for little interpretation with regard to the relationship between taxa and their origins.

\section{Floristic composition}

Most of the literature on seaweed biogeography is in this category. The basic method is to discuss the flora of a given region with respect to the number of species that overlap with other areas as well as the number of endemic species, and to relate this to the principal environmental discontinuities. In this way floristic provinces can be defined and the affinities of the flora determined. The analysis is through a straightforward tabulation of the species and their known distributions, and the calculation of percentages that occur in each biogeographic category. Some examples of this kind of analysis include Parsons (1985) for New Zealand, Schneider (1976) for the Carolinas and Womersley (1981) for Australia. This might be considered the classical approach to seaweed biogeography. It is primarily descriptive and little concrete explanation is provided regarding the historical causes for affinities to various other floras.

A more quantitative approach to the comparison of floras has been undertaken with the primary methods utilized including cluster analysis and various kinds of ordination (e.g. Lawson, 1978; van den Hoek, 1975, 1984; Joosten \& van den Hoek, 1986). Such methods are particularly useful in that they graphically portray the similarity among a large number of floras. These methods are limited, however, in that they do not lead directly to any of the processes that would account for the distributions of constituent taxa. This can only be resolved through a clear understanding of relationships of the various taxa, e. g. the species within a genus or the genera within a family. Evolutionary and historical implications are confounded in the analysis by cosmopolitan and endemic taxa and the fact that different groups of species may have very different origins. These problems are analagous to those in applying cluster analysis to taxonomic problems.

\section{Spans and speciation}

Attempts to relate patterns of speciation and evolution in marine algae to their distribution patterns were carried out by Pielou (1977, 1978). The 1977 study examined the distributions of seaweeds along the entire eastern coastline of the American continents, and the 1978 study the western coastline of the Americas. In an interesting mathematical treatment, she looked at the overlap of species distributions (termed spans) 
of congeners, and examined the extent to which congeners were more likely to have overlapping distributions than species in different genera. This data was then used as a test of various models of speciation, particularly.allopatric versus sympatric speciation. Despite the elegance of the mathematical treatment, this work was flawed in at least two aspects: (1) where an individual species had a disjunct distribution, it was treated for analytical purposes to have a single continuous distribution, and (2) all species and genera were treated regardless of their distribution outside the range being considered, i. e. coastal regions not part of the eastern or western Americas.

The first problem raised above may result in two species having overlapping spans when they are in fact disjunct. For example, if one species occurred in regions $\mathrm{A}$ and $\mathrm{C}$, and a second species occurred in intervening region $B$, then the entire distribution of the second species is considered to overlap with that of the first even though there may be no sympatry whatever. This is a biological oversimplification and confounds attempts to arrive at evolutionary conclusions.

Of the two points raised above, I regard the second as being the most important. To discuss speciation in a genus when there is no evidence that the species involved are sister taxa or closely related within the genus introduces theoretical problems. It assumes that the species present within each genus in the eastern Americas form monophyletic groups. Because most algal genera are widely distributed, the validity of this assumption is highly problematical. Operationally, a way out of this impasse would have been to consider only those taxa (at any hierarchical rank) that were endemic to the relevant coastlines. Additionally, the taxa cannot be monotypic. Pielou's methodology would work best if there were only two taxa in the group being considered. In this way, the underlying assumption that monophyletic groups were present would have been met, at least to the extent that original distributional information was accurate. Had this been carried out, more realistic tests of Pielou's hypotheses would have been made. Cladistic analyses in even a few genera would have given the hypotheses greater biogeographic significance.

\section{LONG-DISTANCE DISPERSAL}

The occurrence and extent of long-distance dispersal provides a central problem in biogeographic analysis of any group of organisms but especially so with seaweeds. A preliminary review of this phenomenon is provided by van den Hoek (1987). The best evidence that long-distance dispersal occurs comes from volcanic oceanic islands which have had no known connection with a continental or other land mass.

It is clear that long-distance transport of marine algae (with or without subsequent speciation) has occurred in the past and may account for the origin of large numbers of disjunct species and or closely related species in widely separated floras (e. g. Hommersand, 1972, 1986). It is dangerous, however, to assume without clear evidence that such a process has been operating (e.g. as in transport to oceanic islands), since disjunct distributions might have arisen through the splitting up of an ancestral, widely distributed biota rather than the transport of species from one place to another. If the occurrence of long-distance dispersal is an a priori assumption of a biographic analysis, it is difficult not to come to the conclusion that it is operating in a particular flora or group of organisms. Vicariance biogeography has the advantage of not being based on concepts 
of dispersal; as a result, long-distance dispersal can be invoked as a default explanation, when other processes cannot be utilized because of the structure of the cladograms.

\section{PANBIOGEOGRAPHY}

This term applies to a biogeographic method advocated by Croizat (e.g. 1964) and more recently by Craw (1983) and Craw \& Weston (1984). Although the methodology of Croizat and his proponents has been strongly criticized on procedural and philosophical grounds (Seberg, 1986), it will likely remain a widely used methodology because it does not rely on cladograms for its basic interpretation. Panbiogeography involves the analysis of 'tracks'; a track being "a line drawn on a map of the geographic distribution of a particular taxon ... that connects the disjunct collection localities of the subordinate taxa comprising the taxon in three or more areas" (Craw, 1983). Different organisms might show similar tracks because the same climatic and/or geological phenomena were acting to produce similar dispersal patterns in the ancestral biotas. Thus the presence of a track connecting two areas suggests the presence of an ancestral flora (and fauna) in the connected regions. The greater the number of organisms that have similar tracks allows for greater levels of explanation, i. e. 'generalized tracks'. Generalized tracks are regarded as strong hypotheses that can be corroborated by geological evidence or even suggest alternative geological models.

Although panbiogeography seems to have been superceded by vicariance biogeography, it may be a useful tool in studying marine distributions of intertidal or shallow subtidal organisms where no truly pelagic phase is known, e.g. seaweeds and seagrasses. The distributions of such organisms are limited by the occurrence of shallow waters on margins of land masses, thus the tracks are more easily defined than they are for terrestrial organisms. With current knowledge of sea level changes and plate tectonics, it should be possible to begin reconstructing scenarios for the dispersal (i. e. track formation) and evolution of particular seaweed groups. Hommersand (1972) provided such an analysis in his comparison of the floras of Pacific North America and Japan. Numerous species (or closely related species) or red, brown and green seaweeds were listed that showed this distribution and an explanation was provided based on transport via the Kuroshio Current prior to Pleistocene glaciation. This connection between Asia and North America would certainly be a generalized track in the sense of Croizat. Papenfuss (1972) also discusses the distributions of some tropical marine algae, and his approach is along the lines of panbiogeography. The Laminariales would be particularly appropriate for this kind of analysis, especially since the distributions for most species have been defined.

Track analysis is analagous to the extensive biogeographic literature on seaweeds in which floristic composition in a particular area is discussed in terms of number of species that are common to other geographic areas. Although rarely stated explicitly, it is implicit in such comparisons that the disjunct taxa had a common origin that can be explained through historical reconstruction.

The analysis of Hommersand (1986) of the biogeography of South African rhodophytes is in the tradition of panbiogeography and this study represents one of the most sophisticated discussions of seaweed biogeography. Tracks connecting southern Africa and other regions were hypothesized based on common occurrence of the same taxon or 
presumed close relationship of congeners. The primary track connected the East Cape and Natal regions with the tropical flora of the Indian Ocean, with secondary tracks involving connections between South Africa and western Australia, and between South Africa and Japan. These distributions were explained based on paleoceanographic changes occurring in the Cenozoic with the flora attaining its current composition during the Oligocene and Miocene. Hommersand also suggest that many taxa (see paper for generic examples) in the northern hemisphere in both Europe and western North America are derived originally from South Africa since the Miocene. Despite the highly speculative nature of this paper, it represents one of the milestones in seaweed biogeography because of the historical and evolutionary basis of the argumentation. One of the strengths of this work is that numerous concrete hypotheses are elaborated that can be tested using the methods of vicariance biogeography.

Nicholson (1979) provided a discussion of Macrocystis which investigated questions concerning the age and origin of the genus and its species, and their mechanism of dispersal to present localities. The reliance on continental drift is of interest in this work. The utility of the hypotheses and conclusions in this study are weakened because of the lack of information on the phylogenetic relationships within the genus, and the absence of any interpretation of the identity of the outgroup. Both of these are a central part of vicariance biogeography.

\section{VICARIANCE BIOGEOGRAPHY}

Vicariance biogeography is the synthesis of the phylogenetic methods of Hennig, i. e. cladistics and the panbiogeography of Croizat (see Brundin, 1981; Nelson \& Platnick, 1981; Wiley, 1981 for reviews). Although Croizat has rejected this synthesis (e. g. Croizat, 1984 and elsewhere), vicariance biogeography has become a widely accepted method for examining the relationship between the systematics of groups and the distribution of the constituent taxa. The ability of vicariance to deal with concrete hypotheses of evolutionary biogeography is unmatched by any other methodology.

The premise on which vicariance biogeography is based is that there is a strong congruence between the evolutionary history of taxonomic groups and the geological history of the areas inhabited by the organisms. Thus cladograms of organisms can be compared with cladograms for areas. This relationship occurs because most speciation events are allopatric and result from the successive sundering of distributions of ancestral taxa. To the extent that this is the case, the sister group relationships of taxa are a reflection of the sister group relationships of areas. When sister group relationships within a particular taxon are reflected by geological history, this is considered support for the vicariance model. When different groups of organisms inhabiting the same overall area show congruence between cladograms and areas, this is also support for a vicariance model even if it is contrary to presumed geological history. This would provide evidence that the geological history as outlined was incorrect and/or provide support for alternative geological models. Thus the methodology of vicariance biogeography is not secondary to geology, but the congruence (or lack of same) can be used to formulate and test hypotheses derived from the other. A more elaborate outline of the theory and practice of vicariance biogeography in the context of seaweeds is provided by Lindstrom (1987) and this material is not repeated here.

The primary strength of the vicariance method is the absence of a priori assumptions 
as to the mode of origin of taxa and their mechanisms of dispersal and speciation. Because these are not assumed at the start of the investigation, hypotheses, in the sense of Ball (1976), that test various models can be evaluated.

Vicariance methodology is particularly appropriate for seaweeds because of the classical emphasis on taxonomy and floristics. Thus we know a considerable amount regarding the extent and nature of endemism in most seaweed floras and the foundations 'for carrying out cladistic analysis of most groups has been established. Some groups of seaweeds where this methodology should yield fruitful results include: Laminariales, Fucales, Corallinales, and Ceramiales. See Lindstrom (1987) for further examples particularly relating to circumarctic floras. Prud'Homme van Reine (1982) provided a cladistic analysis of the European Sphacelariales, although a biogeographic interpretation was not undertaken. These techniques have not been utilized elsewhere in marine algal studies; however, Proctor (1980) provided a detailed cladistic and vicariance analysis of the freshwater genus Chara. The latter study is an excellent model for future work on algae.

Olsen-Stojkovich et al. (1986) provided an elegant analysis of the Cladophorales complex based on the determination of immunological distance measures. Trees that were interpreted as phylogenetic reconstructions, were produced based on cluster analysis and FITCH tree construction. Biogeographic implications of the trees were then discussed. Although the procedures are superficially similar to vicariance methodology, the Olsen-Stojkovich et al. study should not be considered in this light. First, the trees presented do not represent nested synapomorphies and are therefore not cladograms in a Hennigian sense. Secondly, as the authors point out "there is very little provincial endemism " and in such cases elaborate vicariance explanations are not forthcoming. The methodology employed in this paper might be particularly useful in indicating biochemical differentiátion in populations that are morphologically undifferentiated. Similarly, isozyme studies such as those discussed by Innes (1984) would be useful; however, it should be noted that there are considerable problems in giving phylogenetic interpretations to such data types (Farris, 1981).

As van den Hoek (1984) remarks ". . rhodophytan genera are not distributed across the world's oceans in a haphazard way, but according to certain patterns." Van den Hoek's work (1984 and elsewhere) has gone a long way towards establishing what those patterns are, and he has provided a number of scenarios that attempt to explain them. However, the phenetic methods of van den Hoek (1984) and Joosten \& van den Hoek (1986) will not provide a suitable test of those hypotheses; such can best be accomplished through the formulation of falsifiable phylogenetic models that are at the centre of cladistics and vicariance biogeography.

\section{CONCLUSIONS}

Vicariance biogeography provides the most powerful technique presently available for understanding the relationship between the evolution of organisms and their distributions. To the extent that most seaweed floras have a large endemic species component or taxa with restricted distributions, vicariance is an appropriate methodology. Other methods of biogeographic interpretation are less satisfactory either in that hypotheses cannot be rigorously tested or they deal with ecological and/or physiological aspects of distribution. 
Acknowledgements. I would like to thank Dr. K. Lüning for inviting me to present part of this work at the Biogeography Workshop in Helgoland. Dr. S. Lindstrom kindly provided a copy of her manuscript prior to publication. Ms. R. Lewis provided valuable criticism of the manuscript. This work was supported by Natural Sciences and Engineering Research Council of Canada Grant A2931.

\section{LITERATURE CITED}

Ball, I. R., 1976. Nature and formulation of biogeographical hypotheses. - Syst. Zool. 24, 407-430.

Bird, C. J. \& McLachlan, J., 1986. The effect of salinity on distribution of species of Gracilaria Grev. (Rhodophyta, Gigartinales): an experimental assessment. - Botanica mar. 29, 231-238.

Bolton, J. J., 1986. Marine phytogeography of the Benguela upwelling region on the west coast of southern Africa: a temperature dependent approach. - Botanica mar. 29, 251-256.

Brundin, L. Z., 1981. Croizat's panbiogeography versus phylogenetic biogeography. In: Vicariance biogeography. Ed. by G. Nelson \& D. E. Rosen. Columbia Univ. Press, New York, 94-158.

Chapman, V. J. \& Chapman, D. J., 1976. Life forms in the algae. - Botanica mar. 19, 65-74.

Cheney, D. F., 1977. R \& C/P - a new and improved ratio for comparing seaweed floras. - J. Phycol. 13 (Suppl.), 12.

Craw, R. C., 1983. Panbiogeography and vicariance cladistics: are they truly different? - Syst. Zool. $32,431-438$.

Craw, R. C. \& Weston, P.,1984. Panbiogeography: a progressive research program? - Syst. Zool 33, $1-13$.

Croizat, L., 1964. Space, time, form: the biological synthesis. Croizat, Caracas, 881 pp.

Croizat, L., 1984. Mayr vs. Croizat: Croizat vs. Mayr - an enquiry. - Tuatara 27, 49-66.

Farris, J. S., 1981. Distance data in phylogenetic analysis. In: Advances in cladistics. Ed. by V. A. Funk \& D. R. Brooks. New York Botanical Garden, Bronx, 3-23.

Feldmann, J., 1937. Recherches sur la végétation marine de la Méditerranée. La côtes des Albères. Revue algol. 10, 1-339.

Garbary, D., 1976. Life-forms of algae and their distribution. - Botanica mar. 19, 97-106.

Hoek, C. van den, 1975. Phytogeographic provinces along the coasts of the northern Atlantic Ocean. - Phycologia 14, 317-330.

Hoek, C. van den, 1984. World-wide latitudinal and longitudinal seaweed distribution patterns and their possible causes, as illustrated by the distribution of Rhodophytan genera. - Helgoländer Meeresunters. 38, 227-257.

Hoek, C. van den, 1987. The possible significance of long-range dispersal for the biogeography of seaweeds. - Helgoländer Meeresunters. 41, 261-272.

Hommersand, M. H., 1972. Taxonomic and phytogeographic relationships of warm temperate marine algae occurring in Pacific North America and Japan. - Proc. int. Seaweed Symp. 7, 66-71.

Hommersand, M. H., 1986. The biogeography of the South African marine red algae: a model. Botanica mar. 29, 257-270.

Innes, D. J., 1984. Genetic differentiation among populations of marine algae. - Helgoländer Meeresunters. 38, 401-417.

Joosten, A. M. T. \& Hoek, C. van den, 1986. World-wide relationships between red seaweed floras: a multivariate approach. - Botanica mar. 29, 195-214.

Lamouroux, M., 1826. Mémoire sur la géographie des plantes marines. - Annls Sci. nat. (Sér. 1) 7. 60-82.

Lawson, G. W., 1978. The distribution of marine algal floras in the tropical and subtropical Atlantic Ocean: a quantitative approach. - Bot. J. Linn. Soc. 76, 177-193.

Lindstrom, S. C., 1987. Possible sister groups and phylogenentic relationships among selected North Pacific and North Atlantic red algae. - Helgoländer Meeresunters. 41, 245-260.

Lüning, K., 1984. Temperature tolerance and biogeography of seaweeds: the marine algal flora of Helgoland (North Sea) as an example. - Helgoländer Meeresunters. 38, 305-317.

Lüning, K., 1985. Meeresbotanik. Thieme, Stuttgart, 375 pp.

McLachlan, J. \& Bird, C. J., 1984. Geographical and experimental assessment of the distribution of Gracilaria species (Rhodophyta: Gigartinales) in relation to temperature. - Helgoländer Meeresunters. 38, 319-334. 
Nelson, G. \& Platnick, N. I., 1981. Systematics and biogeography: cladistics and vicariance, Columbia Univ. Press, New York, 567 pp.

Nicholson, N. L., 1979. Evolution within Macrocystis: northern and southern hemisphere taxa. - Inf. Ser. N. Z., Dep. scient. ind. Res. 137, 433-441.

Olsen-Stojkovich, J., West, J. A. \& Lowenstein, J. M., 1986. Phylogenetics and biogeography in the Cladophorales complex (Chlorophyta): some insights from immunological distance data. Botanica mar. 29, 239-249.

Papenfuss, G. F., 1972. On the geographic distribution of some tropical marine algae. - Proc. int. Seaweed Symp. 7, 45-51.

Parsons, M. J., 1985. New Zealand seaweed flora and its relationships. - N. Z. J mar. Freshwat. Res. $19,131-138$.

Pielou, E. C., 1977. The latitudinal spans of seaweed species and their patterns of overlap. - J, Biogeogr. 4, 299-311.

Pielou, E. C., 1978. Latitudinal overlap of seaweed species: evidence for quasi-sympatric speciation. - J. Biogeogr. 5, 227-238.

Proctor, V. W., 1980. Historical biogeography of Chara (Charophyta): an appraisal of the BraunWood classification plus a falsifiable alternative for future consideration. - J. Phycol. 16, 218-233.

Prud'Homme van Reine, W. F., 1982. A taxonomic revision of the European Sphacelariaceae (Sphacelariaceae, Phaeophyceae). Brill, Leiden, $293 \mathrm{pp}$.

Rietema, H. \& Hoek, C. van den, 1984. Search for possible latitudinal ecotypes in Dumontia contorta (Rhodophyta). - Helgoländer Meeresunters. 38, 389-399.

Schneider, C. W., 1976. Spatial and temporal distributions of the benthic marine algae on the continental shelf of the Carolinas. - Bull. mar. Sci. 26, 133-151.

Seberg, O., 1986. A critique of the theory and methods of panbiogeography. - Syst. Zool. 35, 369-380.

Setzer, R. B., 1974. Preliminary investigations of benthic marine algae from the breakwaters protecting Los Angeles and Long Beach Harbors. - Mar. Stud. San Pedro Bay., Calif. 4, 89-101.

Silva, P. C., 1979. The benthic algal flora of central San Francisco Bay. In: San Francisco Bay, the urbanized estuary. Ed. by T. J. Conomos. Pac. Div., Am. Acad. Adv. Sci., San Francisco, 287-345.

Thom, R. M., Ármstrong, J. W., Staude, C. P., Chew, K. K. \& Norris, R. E., 1976. A survey of the attached marine flora at five beaches in the Seattle, Washington, area. - Syesis 9, 267-275.

Widdowson, T. B., 1971. Changes in the intertidal algal flora of the Los Angeles area since the survey by E. Yale Dawson in 1956-1959. - Bull. Sth. Calif. Acad. Sci. 70, 2-16.

Wiley, E. O., 1981. Phylogenetics. Wiley, New York, $439 \mathrm{pp}$.

Womersley, H. B. S., 1981. Biogeography of Australasian marine macroalgae. In: Marine botany. Ed. by M. N. Clayton \& R. J. King. Longman Cheshire, Melbourne, 292-307.

Yarish, C., Breeman, A. M. \& Hoek, C. van den, 1984. Temperature, light, and photoperiod responses of some northeast American and west European endemic rhodophytes in relation to their geographic distribution. - Helgoländer Meeresunters. 38, 273-304.

Yarish, C., Breeman, A. M. \& Hoek, C. van den, 1986. Survival strategies and temperature responses of seaweeds belonging to different biogeographic distribution groups. - Botanica mar. 29, 215-230. 